\title{
Optic nerve hypoplasia and astigmatism: a new association
}

Department of Ophthalmology, Royal Hospital for Sick Children, Yorkhill, Glasgow G3 8S J

Correspondence to: S M Zeki. Accepted for publication 4 January 1990

Sabah M Zeki

\begin{abstract}
Thirty-one patients with optic nerve hypoplasia (ONH) or septo-optic dysplasia and two patients with segmental ONH underwent retinoscopy. The results were compared with those of 20 normal subjects. There was a higher prevalence of astigmatism in the patients than in the controls. Two patients with segmental ONH had no evidence of astigmatism. The association of astigmatism with ONH has not hitherto been reported. The close association of ONH with astigmatism highlights the importance of performing careful retinoscopy in children with ONH or septooptic dysplasia in order to identify and correct errors of refraction, thereby optimising visual function and diminishing the likelihood of the development of superadded amblyopia.
\end{abstract}

Optic nerve hypoplasia (ONH) is a nonprogressive congenital abnormality of one or both optic nerves associated with a diminished number of axons. ${ }^{12}$ It causes various degrees of defective vision ranging from minimal visual impairment to total blindness. Bilateral disease has increasingly been reported as being commoner than unilateral disease. ${ }^{3-5} \mathrm{ONH}$ often does not represent simply an isolated ocular anomaly. Several clinically important endocrine and central nervous system abnormalities are now recognised as associated conditions ${ }^{467}$ as well as a large number of systemic abnormalities. ${ }^{158}$ Lambert $e t a l^{5}$ have produced a useful comprehensive review of the literature on $\mathrm{ONH}$. Segmental $\mathrm{ONH}^{9}$ and tilted discs in association with $\mathrm{ONH}^{10}$ have also been described.

\section{Patients and methods}

Thirty-three patients with $\mathrm{ONH}$ underwent retinoscopic examination. Four of them had unilateral ONH and two had unilateral segmental ONH. They had been identified from the inpatient disease index of the Royal Hospital for Sick Children (RHSC) and the RHSC Outpatient Department diagnostic index maintained by the consultant staff. Two of the patients were identified in the eye department at Aberdeen Royal Infirmary and were also included in the study (with permission of the head of the department). Moreover, two patients were referred to the author during the period of the study.

All patients with non-segmental $\mathrm{ONH}$ also had disc-macula/disc diameter ratio of over $3 \cdot 1$ which is characteristic of the condition. ${ }^{112}$ Only one patient (no. 16) showed no double ring sign. However, she had severe constriction of the visual fields, hypothalamic obesity, cerebral palsy, and mental retardation. Comparing the diameter of her optic discs with the width of the slit-lamp beam, on contact lens biomicroscopy, showed her optic discs to have $1 \mathrm{~mm}$ diameter (average disc diameter in normal persons is 1.42 (SD $0 \cdot 24)$ $\mathrm{mm}) .^{13}$ Eighteen normal children from a local primary school were also tested (after the parents had consented to their child's being refracted), and two normal adult volunteers were refracted to make a total number of 20 normal subjects. All patients and control subjects received one drop of $1 \%$ cyclopentolate to induce cyclolegia in each eye half an hour before retinoscopy.

Retinoscopy was performed by using the right eye of the examiner to test the right eye of the patient and the left eye of the examiner to test the left eye of the patient. It was performed from a distance of two-thirds of a metre and as close to the visual axes of the patients as possible. The patients and the normal subjects were encouraged to look at a target positioned $6 \mathrm{~m}$ away. Retinoscopy was performed on all patients and normal subjects by the author.

For the purpose of statistical analysis of data the mean for the two eyes was taken as the datum value for a subject unless only one eye had been assessed, in which case the value for that eye was taken. The rationale for this type of analysis has been described previously. ${ }^{1+15}$

\section{Results}

The normal group was divided into two according to age. The first group comprised nine subjects aged 4 to 7 , and the second group comprised 11 normal individuals between the ages of 8 and 35 . The two groups were compared. There was no statistically significant difference between the two age groups in the normal control group either with regard to the total spherical power ( $t$ test, $\mathrm{p}>0.5)$ or astigmatism ( $t$ test, $\mathrm{p}>0.5$ ).

The correlation coefficient for the age variation of the total spherical power in the two groups of normal subjects was not significant (Pearson correlation coefficient, $\mathrm{p}>0 \cdot 1$ ). The mean total spherical power of the right eye in the younger group was $+2 \cdot 35$ dioptres, while the mean of the total spherical power of the right eye in the older group was $+2 \cdot 20$ dioptres. The mean astigmatism in the younger group was $0 \cdot 14$ dioptre in the right eye, while it was $0 \cdot 20$ for the right eye in the older group. The mean astigmatism in the left eye was $0 \cdot 17$ dioptre in the first group and $0 \cdot 20$ in the second.

The correlation coefficient between the mean total spherical power and age among the patient group was not significant (Pearson correlation coefficient, $p>0 \cdot 1$.

Astigmatism was common in the 58 eyes of patients with ONH (apart from the two patients 
TABLE I The findings of retinoscopy in the patient group

\begin{tabular}{|c|c|c|c|c|c|c|}
\hline \multirow[b]{2}{*}{ Patient } & \multirow{2}{*}{$\begin{array}{l}\text { Age } \\
\text { (years) }\end{array}$} & \multirow[b]{2}{*}{ Sex } & \multicolumn{2}{|c|}{ Total spherical power } & \multicolumn{2}{|c|}{ Astigmatism } \\
\hline & & & $O D$ & os & $O D$ & os \\
\hline 1 & 6 & F & $2 \cdot 25$ & $2 \cdot 5$ & 1.5 & 0 \\
\hline 2 & 4 & $M$ & 1.75 & 0.75 & 1.5 & 0.5 \\
\hline $\begin{array}{l}3 \\
4\end{array}$ & 3 & $\mathrm{~F}$ & $\begin{array}{l}1.62 \\
3.75\end{array}$ & $\begin{array}{l}1.12 \\
2.87\end{array}$ & $\begin{array}{l}0.25 \\
0.5\end{array}$ & $\begin{array}{l}0.75 \\
0.75\end{array}$ \\
\hline $\begin{array}{l}4 \\
5\end{array}$ & $\begin{array}{l}4 \\
3\end{array}$ & $\mathrm{~F}$ & -4.62 & $\begin{array}{r}2.81 \\
-37\end{array}$ & 0.75 & $1 \cdot 25$ \\
\hline 6 & 4 & $\mathrm{~F}$ & $6 \cdot 25$ & 7 & ? & 1.5 \\
\hline 7 & 4 & $\mathbf{F}$ & $-2 \cdot 5$ & $-3 \cdot 25$ & & $3 \cdot 25$ \\
\hline 8 & 4 & $\mathbf{F}$ & $3 \cdot 12$ & $3 \cdot 12$ & $0 \cdot 25$ & 0.25 \\
\hline 9 & 8 & $M$ & 2 & $2 \cdot 12$ & 0.5 & 1.75 \\
\hline 10 & 17 & M & $-2 \cdot 25$ & -0.87 & 6 & $3 \cdot 25$ \\
\hline 11 & 21 & $\mathrm{~F}$ & $0 \cdot 12$ & 0.00 & 1.75 & 1.5 \\
\hline 12 & 1 & $\mathrm{~F}$ & $4 \cdot 25$ & 4.75 & i & 0.5 \\
\hline 13 & 19 & $\mathrm{~F}$ & $1 \cdot 37$ & $2 \cdot 62$ & 0.75 & $2 \cdot 75$ \\
\hline 14 & 11 & $M$ & 1.25 & $1 \cdot 12$ & 4 & 4.25 \\
\hline 15 & 3 & M & 1.62 & 0.5 & 1.25 & 1.5 \\
\hline 16 & 2 & M & $2 \cdot 25$ & $2 \cdot 12$ & 0.5 & 0.25 \\
\hline 17 & 7 & $\mathbf{M}$ & $3 \cdot 37^{\star}$ & 3.5 & $0.25^{\star}$ & 0.5 \\
\hline 18 & 15 & $\mathbf{F}$ & $-1 \cdot 37$ & $-1 \cdot 37$ & $4 \cdot 25$ & $4 \cdot 25$ \\
\hline 19 & 8 & $\mathbf{F}$ & $2 \cdot 12^{\star}$ & $2 \cdot 67$ & $0 \cdot 25^{\star}$ & 0.75 \\
\hline 20 & 2 & M & $2 \cdot 5$ & $2 \cdot 5$ & 1.5 & 2 \\
\hline 21 & 16 & M & $1 \cdot 25$ & 0.75 & 0.5 & 0.5 \\
\hline 22 & 7 & $\mathrm{~F}$ & $5^{\star}$ & $3 \cdot 75$ & $0.00^{\star}$ & \\
\hline 23 & 6 & M & $1 \cdot 12$ & $2 \cdot 37$ & 2.75 & $2 \cdot 25$ \\
\hline 24 & 14 & $M$ & 0.5 & 0.37 & 2.5 & 2.25 \\
\hline 25 & 7 & $M$ & 1.5 & 2.5 & 1.5 & 2.5 \\
\hline 26 & 7 & M & 0.25 & $-2 \cdot 25$ & 1.25 & 2.25 \\
\hline 27 & 26 & $\mathrm{~F}$ & 1.75 & 1.75 & 0.5 & 0.5 \\
\hline 28 & 4 & M & $4 \cdot 5$ & 5 & 0.5 & 1 \\
\hline 29 & 19 & $M$ & 1.5 & 2.37 & 0.5 & 0.25 \\
\hline 30 & 4 & $M$ & 2 & 2.62 & 1 & 1.75 \\
\hline $31 \neq$ & 9 & $F$ & 3 & 3 & 0.00 & 0.00 \\
\hline 32 & 43 & $F$ & † & 0.5 & $t$ & 0.5 \\
\hline $33 \neq$ & 22 & $\mathbf{F}$ & 1.75 & 1.75 & 0.00 & 0.00 \\
\hline
\end{tabular}

*Findings in eyes which were deemed not to have $\mathrm{ONH}$ tThis patient's right eye had high myopia, dense amblyopia, and a visual acuity of light perception only.

$\ddagger$ Patients with segmental ONH.

with segmental ONH, who had no astigmatism) when compared with the normal subjects (Table I). This was statistically highly significant (Mann-Whitney test and Welch's test, $\mathrm{p}<0.001$ ). The mean astigmatism in the right and left eyes with $\mathrm{ONH}$ was 1.53 and 1.52 dioptres respectively. The proportion of patients with $\mathrm{ONH}$ who had astigmatism greater than 0.5 dioptre was

TABLE II Visual acuities with and without correction

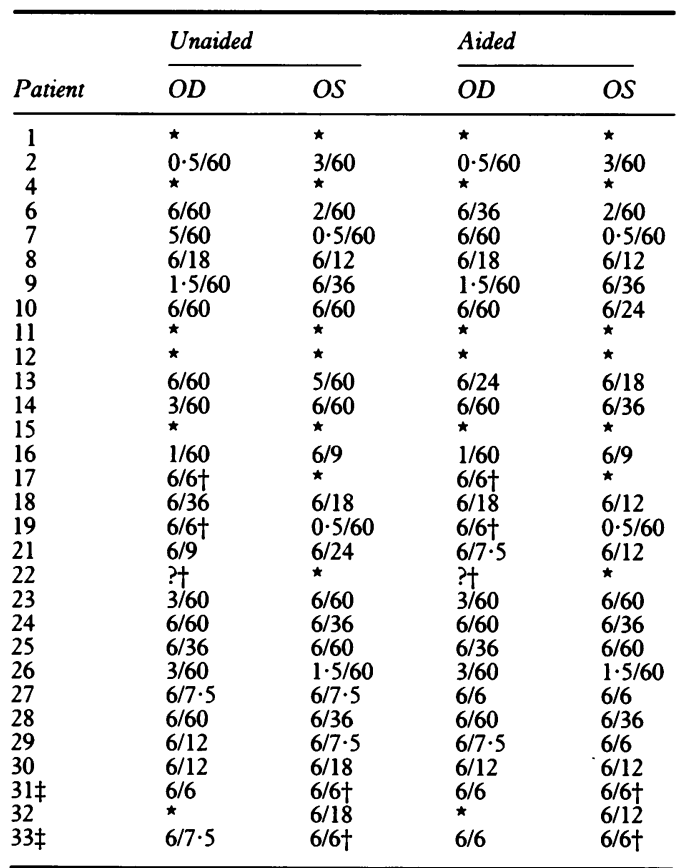

Blind eye.

†Eyes which were deemed not to have ONH.

$\Varangle$ Patients with segmental ONH.

$?=$ The visual acuity of this patient could not be subjectively tested.
$62 \%$ in the 27 right eyes with ONH and $66.5 \%$ in the patient group's 31 left eyes with $\mathrm{ONH}$ (apart from the two patients with segmental $\mathrm{ONH}$ ). Only one subject in the normal group had astigmatism of greater than 0.5 dioptre in her left eye $(0.75$ dioptre). Furthermore, one patient (no. 26) who had left unilateral ONH showed no astigmatism in the right eye, while in the eye with $\mathrm{ONH}$ (left eye) he had 2 dioptres of astigmatism. Of the other three patients with unilateral optic nerve hypoplasia one had a highly myopic blind eye, and her other eye had $\mathrm{ONH}$ with astigmatism of 0.5 dioptre. Of the remaining two patients one had 0.25 dioptre astigmatism in the normal eye (but she had a $0 \cdot 75$ dioptre of astigmatism in the eye with $\mathrm{ONH}$ ), and the last patient with unilateral $\mathrm{ONH}$ had 0.25 dioptre of astigmatism in the normal eye and an 0.5 dioptre in the eye with $\mathrm{ONH}$.

Considering the axes of astigmatism in the 58 eyes with $\mathrm{ONH}$, in $63 \%$ of the eyes with astigmatism the axis (of the positive cylindrical lens) was either vertical or horizontal to within $5^{\circ}$. In $37 \%$ the axis was oblique. Seven patients $(23 \%)$ with bilateral ONH had either a horizontal or vertical axis of astigmatism in one eye and oblique axis in the other eye. In only three patients were the axes of astigmatism opposite to each other in the two eyes (within $5^{\circ}$ ).

Patients with bilateral $\mathrm{ONH}$ and whose visual acuities were known were divided into two groups. The first group comprised patients with visual acuities worse than $6 / 36$ in the better eyes (9 patients), and the second group comprised patients with visual acuities of $6 / 36$ or better in the better eyes ( 15 patients). The degrees of astigmatism in the better eyes was compared in the two groups (the average degree of astigmatism for the two eyes was taken for a patient when the visual acuities were the same in the two eyes). There was no statistically significant difference in the severity of astigmatism between the first group (mean 1.23 dioptres), and the second group (mean 1.84 doptres) (Welch's test, $\mathrm{p}>0 \cdot 1$ ).

The mean total spherical power in the normal subjects was $+2 \cdot 26$, while this was $+1 \cdot 6$ for the eyes with $\mathrm{ONH}$ in the patient group. However, this trend was not statistically significant (Welch's test, $0 \cdot 1<\mathrm{p}<0 \cdot 2$ ).

The visual acuities could be assessed in 30 of the patients. The unaided visual acuities ranged from no light perception to $6 / 7 \cdot 5$ (Table II). The unaided visual acuities were $6 / 6$ in the patients with segmental ONH.

\section{Discussion}

The literature on $\mathrm{ONH}$ has been reviewed. ${ }^{16}$ Forty reported cases of $\mathrm{ONH}$ were found in which the refraction had been documented. These were thought to have the same age and sex distribution as the normal population.

The finding in the present paper of a close association of $\mathrm{ONH}$ with astigmatism highlights the importance of careful retinoscopy in a child with $\mathrm{ONH}$, in order to optimise visual acuity which may be already substantially impaired. It is therefore recommended that all such children should be refracted at the earliest opportunity. 
The mean total spherical power in the patient group was $30 \%$ lower than in the normal subjects, suggesting a trend towards myopia. However, this was not found to be statistically significant.

The relationship between $\mathrm{ONH}$ and astigmatism is not known, and further investigation by keratometry may shed further light on the association between the two disorders. It is also important that this study is repeated in other such children in order to determine the overall prevalence of astigmatism in $\mathrm{ONH}$.

I would like to thank Dr Anne Alexander for facilitating access to the control subjects, Dr Gordon N Dutton for his assistance in preparing this paper, and Dr Donald Allan for his help with the preparing this paper, and Dr Donald Allan for his help with the
statistical analysis. I would also like to thank Professor John V statistical analysis. I would also like to thank Professor John V
Forrester and Dr John Dudgeon for facilitating access to patients under their care.

1 Mosier MA, Lieberman MF, Green WR, Knox DL. Hypoplasia of the optic nerve. Arch Ophthalmol 1978; 96: 1437-42.

2 Hotchkiss ML, Green WR. Optic nerve aplasia and hypoplasia. F Pediatr Ophthalmol Strabismus 1979; 16: 22540.

3 Billson FA. Clinical significance of optic nerve hypoplasia. Trans Ophthalmol Soc NZ 1973; 25: 179-80.
4 Acers TE. Optic nerve hypoplasia: septo-optic-pituitary dysplasia syndrome. Trans Am Ophthalmol Soc 1981; 79: dysplasia

5 Lambert SR, Hoyt CS, Narahara MH. Optic nerve hypoplasia. Surv Ophthalmol 1987; 32: 1-9.

6 Margolith D, Jan JE, McCormick AQ, Tze WJ, Lapointe J. Clinical spectrum of optic nerve hypoplasia: review of 51 patients. Dev Med Child Neurol 1984; 26: 311-22.

7 Duke-Elder S. Abnormalities of the optic disc and nerve. In: System of ophthalmology. London: Kimpton, 1964: 669-70.

8 Acers TE. Optic nerve hypoplasia and visual function (a quantitative correlation). $\mathcal{F}$ Okla State Med Assoc 1983; 76: 409-13.

9 Buchanan TA, Hoyt WF. Temporal visual field defects associated with nasal hypoplasia of the optic disc. $\mathrm{Br} \mathcal{F}$ associated with nasal hypoplas
Ophthalmol $1981 ; 65: 636-40$.

10 Dorrell D. The tilted disc. Brf Ophthalmol 1978; 62: 16-20.

11 Awan KJ. Ganglionic neuroretinal aplasia and hypoplasia: aplasia and hypoplasia of optic nerve. Ann Ophthalmol 1976; 8: 1193-202.

12 Wakakura M, Alvarez E. A simple clinical method of assessing patients with optic nerve hypoplasia. The disc-macula distance to disc diameter ratio. Acta Ophthalmol $(K b h)$ 1987; 65: 612-7.

13 Beuchat L, Safran AB. Optic nerve hypoplasia: papillary diameter and clinical correlation. $\mathcal{f}$ Clin Neuro Ophthalmol diameter and clini

14 Ray WA, O'Day DM. Statistical analysis of multi-eye data in ophthalmic research. Invest Ophthalmol Vis Sci 1985; 26: 1186-8.

15 Newcombe RG, Duff GR. Eyes or patients? Traps for the unwary in the statistical analysis of ophthalmological studies. BrF Ophthalmol 1987; 71: 645-6.

16 Zion V. Optic nerve hypoplasia. Ophthalmic Sem 1976; 1: 171- 